\title{
DRY SLIDING WEAR BEHAVIOUR OF MG/TIP (MG)-BASED COMPOSITE OBTAINED THROUGH P/M ROUTE
}

\begin{tabular}{|l|l|l|}
\hline M. Appoothiadigal & Sanket Patro & B.K.Raghunath \\
Dept. of manufacturing Engineering & Dept. of manufacturing Engineering & Dept. of manufacturing Engineering \\
Annamalai University & Annamalai University & Annamalai University \\
Chidambaram, Tamil Nadu, India & Chidambaram, Tamil Nadu, India & Chidambaram, Tamil Nadu, India \\
e-mail: appothii_adigal@yahoo.co.in & e-mail: sankaetpatro08@gmail.com & e-mail: bkrau@ rediffmail.com \\
\hline
\end{tabular}

\begin{abstract}
This paper investigates the wear behavior of $\mathrm{Mg} / \mathrm{Ti}_{\mathrm{p}}$ (Mg)-based composites during dry sliding. Experiments were conducted using a pin-on-disc configuration against a hardened tool-steel counter-face under two different condition of varying speed and varying load keeping other variability constant. The composites exhibit slightly superior wear resistance under the lower load, but the effects of the $\mathrm{Ti}$ particulate reinforcements on wear resistance are not as conclusive under the higher load. Scanning electron microscopic (SEM) examinations of the worn composites identified the following wear mechanisms: abrasion, oxidation, adhesion. The useful range of $\mathrm{Mg} / \mathrm{Ti}_{\mathrm{p}}$ composites appears to be limited to loads and speeds below $98 \mathrm{~N}$ and $450 \mathrm{rpm}$, respectively. Under the sliding conditions, abrasion wear and oxidation wear becomes the dominating wear mechanisms at varying speed case causing gross deformation of the magnesium matrix at the contacting interface, thus rendering any component useless. Where under varying load, at higher load adhesive wear predominates all wear mechanism.
\end{abstract}

Keywords- Mg/Tip (Mg)-based composite, Pin-on-disc wear test apparatus, Ti particulate, Wear mechanisms.

\section{INTRODUCTION}

In the age of metals we have walked miles in obtaining the best couple for an operation. Dependency on needs and obtaining the best effective combination of metal is much necessary. Aerospace and automobile are the sectors requiring materials with high specific strength and stiffness. This leads to gross development of research activities in the fields of tailoring material properties.

In the field of aerospace and automobile the lightest metal performs the best because of its high fuel efficiency [13]. So, much of the research activity aims providing high strength to weight ratio. Rather allowing elements to bond atomically, composite behaves a combination of the properties by fusing of the particles. A number of various combination of material are being tested for attaining some of the optimum properties. Commonly used light materials are aluminium, magnesium, titanium and their alloys. The reinforcement is in the form of fibres, whiskers and particulates.

The ability to combine metallic properties (ductility and toughness) with ceramic properties (high strength and high modulus) leading to great strength in shear and compression and high service temperature capabilities enable the MMCs to meet the requirement of tribological applications [15].

Magnesium matrix composites reinforced with ceramic particles is a result of the fact that these composites possess superior properties and hence are potential candidate materials in number of applications.

Compared to ceramic reinforcement phase, the wettability is more in-case of metal reinforcements.[12] Hence research activity focuses more on reinforcement phase for the matrix. Magnesium combined with titanium particulate have shown enhanced properties in recent research works [19]. Titanium reinforcement induces improved fatigue resistance, increased strength, increasing $0.2 \%$ yield strength and ultimate tensile strength of the matrix [14, 19]. It has been observed that the fracture toughness of the matrix generally decreases with increase in volume fraction of particulate [1]. Whereas the hardness and strength are observed to be increasing with increasing particulate content [9].

The interface between the particles of metal plays a vital role in determining the various mechanical behaviour of the material. An intimate contact between the reinforcement and matrix have to be established through satisfactory wetting of the reinforcement by the matrix. $[2,8,16]$

The prime objective of the experiment is to find the wear behaviour of $\mathrm{Mg} / \mathrm{Ti}_{\mathrm{p}}$ (vol. $8 \%$ ) composite material. And thereby resolving the various wear mechanisms occurred, through Scanning Electron Microscope (SEM).

The induction of metallic phase particle reinforcement improves the lubrication properties of the composite. This improves the tribological properties of the matrix metal. [21] The predominating wear mechanism due to plastic deformation of matrix material has considerably improved by the addition of metallic reinforcement. This generally transforms to three body abrasion when the boding between matrix and reinforcement is poor.[22] 


\section{Asia Pacific Journals}

\section{EXPERIMENTAL PROCEDURE}

\section{A. Material}

The matrix material selected was $\mathrm{Mg} / \mathrm{Ti}_{\mathrm{p}}(8 \%$ vol.) the chemical composition of the matrix material is magnesium $90 \%$ and titanium $8 \%$ of the total volume respectively. Titanium is added as a reinforcement to the base matrix.

\section{B. Preparation of Specimen}

The $\mathrm{Mg} / \mathrm{Ti}_{\mathrm{p}}$ (vol. 8\%) is obtained through powder metallurgy route. Magnesium being the matrix and titanium as reinforcement phase.

Magnesium AZ31 metal powder $(45 \mu \mathrm{m})$ is mixed with fine titanium powder $(10 \mu \mathrm{m})$ using ball milling machine. Zinc metal powder in a very small concentration has been introduced as binder. This accounts $2 \%$ of the total volume.

The material preparation is followed through powder metallurgy route. In cold compaction, a manual hydraulic press of 100 ton is used. To compress the powder mixture within, a high carbon high chromium die/punch (HRC 56) of size $\phi 12 * 55 \mathrm{~mm}$ and clearance $0.001 \mathrm{~mm}$ is used.

Using liquid paraffin as lubricant the powder mixture is compressed to a load of 10 ton manually, where a of size $\phi 12 * 20 \mathrm{~mm}$ cylindrical billet is obtained. Which later machined to the required dimension.

Within a mean interval of time the specimens obtained are sintered to a temperature of $512^{0} \mathrm{C}$ for $2.83 \mathrm{hr}$ under Argon inert gas atmosphere. For this purpose a high temperature tubular furnace is used. The heating rate is maintained at $4^{0}$ $\mathrm{C} / \mathrm{min}$ to facilitate ease evaporation of binder and lubricant trapped in the material during cold compaction and also to initiate the bond formation. After reaching the sintering temperature the specified time is provided. And post sintering temperature/cooling rate is maintained at $25^{\circ} \mathrm{C} / \mathrm{min}$ in the controlled atmosphere.

\section{Hardness test}

Micro hardness measurements were made on the polished samples of the composite. The Vickers microhardness of the composite samples has been measured using a load of $30 \mathrm{~kg}$ for indention diagonal average length $0.5 \mathrm{~mm}$. five set of measurement of microhardness is performed on the sample.

\section{Wear test}

The sliding wear tests were conducted using pin-on-disc wear test apparatus at room temperature of $25^{\circ} \mathrm{C}$ and $50 \%$ relative humidity. The disc of the polishing machine is made of E32 steel (HRC 65), diameter of 250mm, 0.02 um Surface rugosity $(\mathrm{Ra})$ and weighing $5.25 \mathrm{~kg}$. The tests were carried out with varying velocity and loads, the wear time is maintained $16 \mathrm{~min}$ for all sets of measurements. Precision electronic weight balance machine is used to calculate the wear mass loss by weighing specimens before/after wear tests.

\section{E. Microstructure analysis}

The microstructure of the prepared specimen is analysed by using a Scanning Electron Microscope with EDS \& EBSD Systems at $500 \mu \mathrm{m}$ resolution for sintered composite. And the wear surface was analysed at $100 \mu \mathrm{m}$ resolution.

\section{F. Plan of Experimen}

The experimental plan was formulated considering two independent variables, load and sliding speed where the sliding distance was maintained constant. The levels of these variables chosen for experimentation are given in Table I.

TABLE I. PARAMETER AND THEIR LEVELS

\begin{tabular}{|l|l|l|l|}
\hline \multicolumn{1}{|c|}{$\begin{array}{c}\text { Controllable } \\
\text { factor }\end{array}$} & \multicolumn{1}{|c|}{ Load (N) } & \multicolumn{1}{|c|}{$\begin{array}{c}\text { Sliding Speed } \\
\text { (rpm) }\end{array}$} & $\begin{array}{c}\text { Sliding } \\
\text { distance } \\
\text { (mm) }\end{array}$ \\
\hline Level 1 & 98 (Const.) & $\begin{array}{l}150-750 \\
\text { (Varied) }\end{array}$ & 3000 (const.) \\
\hline Level 2 & $\begin{array}{l}49-137 \\
\text { (varied) }\end{array}$ & 570 (Const.) & 3000 (Const.) \\
\hline
\end{tabular}

\section{RESULT AND DISCUSSION}

The experiment is conducted and the wear data were obtained for various combination of parameters as shown in table 1. The microhardness test is performed on the samples and the average hardness values is found as Vickers hardness number (VHN).

\section{A. Wear result}

TABLE II. WEAR BEHAVIOR AT CONSTANT LOAD

\begin{tabular}{|c|c|c|c|c|}
\hline S.No & $\begin{array}{c}\text { Speed } \\
(\mathbf{r p m})\end{array}$ & $\begin{array}{c}\text { Load } \\
(\mathbf{N})\end{array}$ & $\begin{array}{c}\text { Time } \\
(\mathbf{m i n})\end{array}$ & $\begin{array}{c}\text { Wear } \\
(\mathbf{g})\end{array}$ \\
\hline 1 & 150 & 98 & 16 & 0.0004 \\
\hline 2 & 300 & 98 & 16 & 0.0007 \\
\hline 3 & 450 & 98 & 16 & 0.0008 \\
\hline 4 & 600 & 98 & 16 & 0.0010 \\
\hline 5 & 750 & 98 & 16 & 0.0012 \\
\hline
\end{tabular}




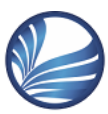

ELK

Asia Pacific Journals

TABLE III. WEAR BEHAVIOR AT CONSTANT SPEED

\begin{tabular}{|c|c|c|c|c|}
\hline S.No & $\begin{array}{c}\text { Speed } \\
(\mathbf{r p m})\end{array}$ & $\begin{array}{c}\text { Load } \\
(\mathbf{N})\end{array}$ & $\begin{array}{c}\text { Time } \\
(\mathbf{m i n})\end{array}$ & $\begin{array}{c}\text { Wear } \\
(\mathbf{g})\end{array}$ \\
\hline 1 & 570 & 49 & 16 & 0.0002 \\
\hline 2 & 570 & 68 & 16 & 0.0005 \\
\hline 3 & 570 & 98 & 16 & 0.0009 \\
\hline 4 & 570 & 117 & 16 & 0.0010 \\
\hline 5 & 570 & 137 & 16 & 0.0011 \\
\hline
\end{tabular}

\section{B. Graphs}

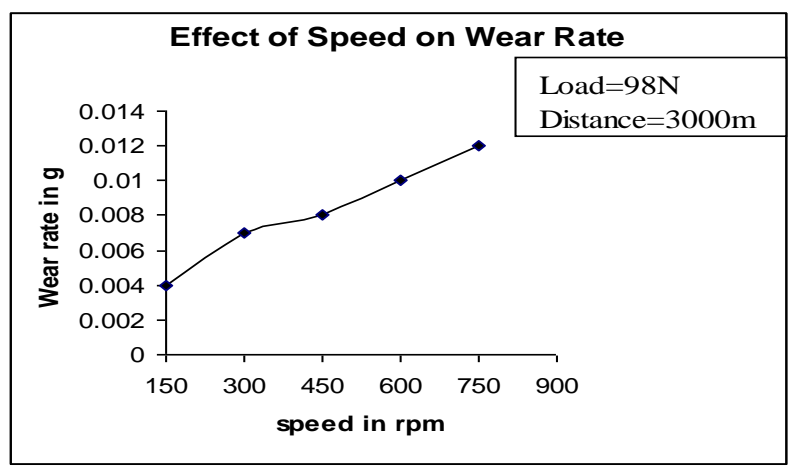

Figure 1 Effect of speed on wear rate

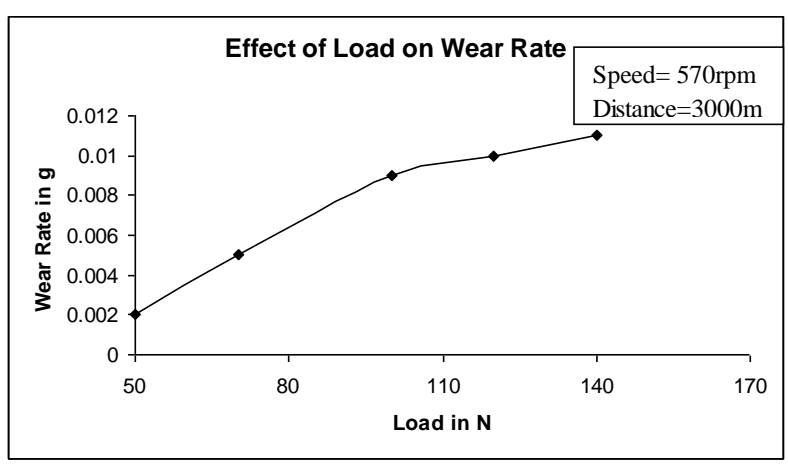

Figure 2 Effect on load on wear rate

\section{Microstructural analysis using Scannning Elecctron Microscope}

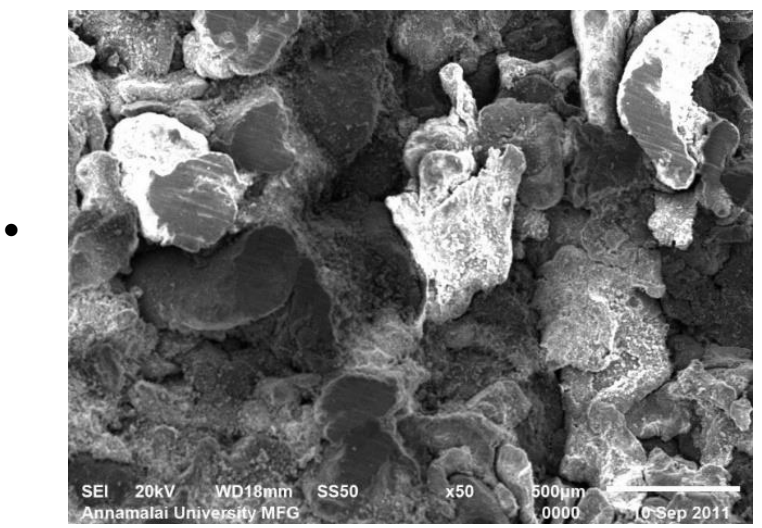

Figure 3 Microstructural image showing composite specimen

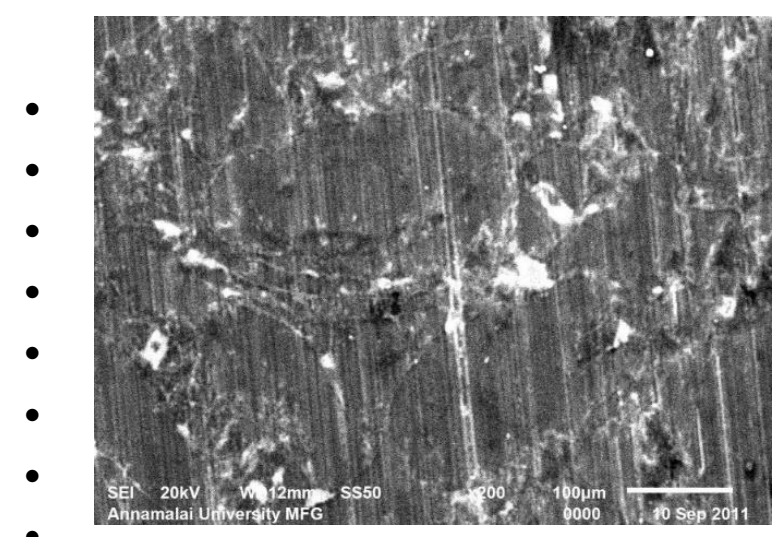

Figure 4 Surface microscopy showing abrasive wear

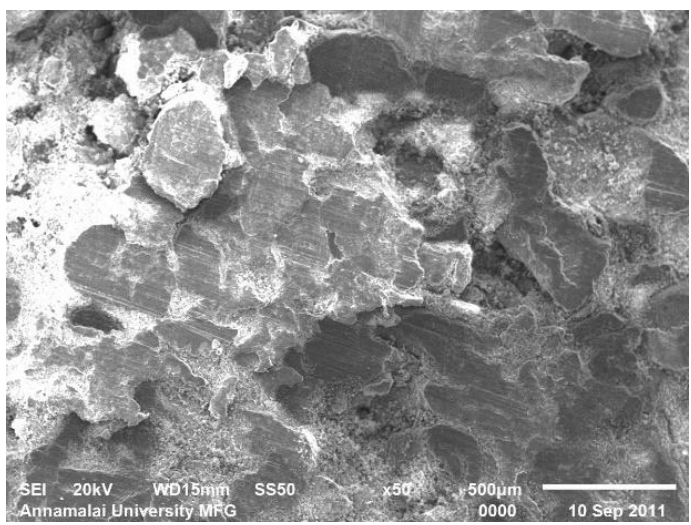

Figure 5 Surface microscopy showing adhesive wear

The result of wear data shows increasing rate of wear with increasing load and speed respectively.

The scanning electron microscopy results of wear specimen shows, encase of increasing speed at constant load Fig.4, Abrasive wear and oxidation wear are the predominant wear mechanisms causing material removal. Where as in the latter case Fig.5, the increasing load leads to plastic flow of material with the increasing heat, and thereby causing adhesive wear and oxidation wear as predominant wear mechanism in material removal.

The microstructural image Fig.3, of composite specimen shows uniform distribution of $\mathrm{Ti}$ particulates in $\mathrm{Mg}$ matrix. Where in some case the Ti particulate has agglomerated, this doesn't affect much in material property. The porosity of the material is seen to be high, the surface is coarse and hence while sliding the coarse grained particle detaches easily to behave as a third body causing abrasive wear. This has been observed with varying sliding speed. Where $\mathrm{Ti}$ particle accelerates the material removal. 


\section{(2) \\ ELK \\ Asia Pacific Journals}

During sliding the reaction of atmospheric air with specimen resulting oxidation of the material, which leads to oxidation wear. It has been seen in both the case.

The wear plots Fig.1 and Fig.2, shows linear increment in material loss with increasing load and sliding speed.

At low speed, medium load $(150 * 98)$ the wear rate is less compared to high speed medium load $(750 * 98)$. Similarly at low load, moderate speed $(49 * 570)$ is very significant to that of high load moderate speed $(137 * 570)$.

The $8 \%$ volume fraction of $\mathrm{Ti}$ in $\mathrm{Mg}$ matrix has shown considerable effect in increasing wear behaviour of the composite.

\section{Microhardness test}

TABLE IV.

MiCROHARDNESS TEST READINGS

\begin{tabular}{|c|c|c|c|c|}
\hline SI No & Position A & Position B & $\begin{array}{c}\text { Total } \\
\text { Hardness } \\
\text { mm }\end{array}$ & $\begin{array}{c}\text { Vicker's } \\
\text { hardness } \\
\text { (VHN) }\end{array}$ \\
\hline 1 & 2 & 47 & 0.147 & 42.9 \\
\hline 2 & 2 & 45 & 0.145 & 44.1 \\
\hline 3 & 2 & 35 & 0.135 & 50.9 \\
\hline 4 & 2 & 40 & 0.140 & 47.3 \\
\hline 5 & 2 & 16 & 0.116 & 68.9 \\
\hline
\end{tabular}

The micro hardness test shown wealthy result of 50.82 VHN on an average for the $\mathrm{Mg} / \mathrm{Ti}$ (vol. $8 \%$ ) specimen.

\section{CONCLUSION}

From the experimental studied the following aspects are concluded,

1) The microstructural image of the composite shows uniform distribution of $\mathrm{Ti}$ particulate in the $\mathrm{Mg}$ matrix metal. The porosity of the metal is seen to be high and the surface is coarse.

2) An average value of microhardness of the composite is found to be $50.82 \mathrm{VHN}$.

3) Wear result showed abrasion wear as the predominant material removal mechanism encase of increasing speed. Where adhesive wear as predominant encase of increasing load. Oxidation wear is seen in both the cases which reduces with increasing in load and speed respectively.

4) The experimental result showed $L * S * D$ (load $N$, Speed rpm, Distance mm) [49*570*3000] has the least wear rate.
ELK Asia Pacific Journals - Special Issue ISBN: 978-81-930411-4-7

5) At upper moderate speed and low load the material removal is found to very significant compared to other combinations.

6) The wear result is seen to be influenced by the lubrication property of reinforcement particle.

\section{References}

[1] A Review of the Fracture Toughness of particle Reinforced Al alloys. A Mortensen. Sept. 1990. Montreal, Canada : ASM International,, Sept. 1990. Conf. on Fabrication of Particulates Reinforced Metal composites.

[2] Mortensen, I. Jin, Int. 1992. 1992, Material Review 37, pp. 101-123.

[3] Applications of Magnesium in Aerospace. G.B. Evans. 1986. 1986 Magnesium Technological Institute of metals, pp. 103-109.

[4] Clow, B B. 1996. Advanced Material Processes 150 (4). 1996, pp. 33 34.

[5] Corrosion behavior of some vapour deposited magnesium alloy. K.R Baldwin, D.J. Bray, G.D. Howard, R.W. Gardiner, 1996. 1996, Material Science Technology 12, pp. 937-943.

[6] Development of a novel magnesium/nickel composite with improved mechanical properties. S.F. Hassan, M. Gupta. 14 March 2002. 14 March 2002, Journal of Alloys and Compounds, Volume 335, Issues 1 2, pp. L10-L15.

[7] Development of light alloys by rapid solidfication processing. Suryanarayana, C., Sam Froes, F.H., Krishnamurthy, S. and Kim, Y.W 1990. 1990, International journal of powdermetallurgy, Vol.26, n2, pp. 117-129.

[8] F. Delannay, L. Froyen, A. Deruyttere,. 1987. 1987, Journal on material science, 22, pp. 1-6

[9] Ibrahim, F. A. Mohamed, E. J. Lavernia. 1991. 1991, Journal on material science, 26 , pp. 1137-1155

[10] Magnesium alloys and their application. D. Magers, J. Brussels, in: B.L. Mordike, K. U. Kainer. 1998. Wolfsburg, germany: Werkstoffinformationsge-sellschaft, 1998. p. 105.

[11] Magnesium races ahead. H.Baker. 1989. 1989, Advanced Material Processes, pp. 35-42.

[12] Manoj Gupta, Nai Mui Ling Sharon. 31-Mar-2011. Magnesium Composites. Magnesium, Magnesium Alloys, and Magnesium Composites. Singapur : John Wiley \& Sons, 31-Mar-2011, pp. 181-185.

[13] Materials and Design 29. B.K. Raghunath, R. Karthikeyan, G. Ganesan M. Gupta. 2008. 2008, An investigation of hot deformation response of particulate-reinforced magnesium+9\% titanium composite, pp. 622-627.

[14] Metal Trans, 23 A, 2833. Roy, M, B. Venkataraman, V. V. Bhanuprasad, Y.R. Mahajan and G. Sundarajan,. 1992. 1992.

[15] MMCs: Materials, Manufacturing and Mechanical properties. Huda M. D., M. S. J. Hashmi and M. A. El-Baradie. 1995. 1995, Key Engineering Materials, Vol. 104-107, pp. 37-64.

[16] N. Eustathopoulos. 1998. 1998, Acta. Mater. 46, pp. 2319-2327.

[17] Particle Reinforced Aluminium and Magnesium Matrix Composites. Lloyd, D.J,. 1994. 1994, International Material Reviews, Vol. 39, No.1, pp. 1-23.

[18] R.A. Saravanan, M.K Surappa,. 2000. Material Science Engineering A 2761. 2000 


\section{Asia Pacific Journals}

[19] S.F.Hasssan. 2001. Synthesis and Characterization of Reinforced Metal Based. Singapore : M.E. Thesis, National University of Singapore, 2001.

[20] Synthesis, Microstructure and properties characterization of disintegrated meltdeposited $\mathrm{Mg} / \mathrm{SiCp}$ composite. Gupta, M. Lai, M.O. and Saravanaranganathan, D. 2000. 2000, Journal of Material Science, Vol. 35, pp. 2155-2165.

[21] Sliding wear of LM25 aluminium alloy with $7.5 \% \mathrm{SiC}+2.5 \% \mathrm{TiO}_{2}$ and $2.5 \% \mathrm{SiC}+7.5 \% \mathrm{TiO}_{2}$ hybrid composites. G Elagno, BK Raghunath, K Palanlkumar and K Thamizhmaran. Journal of composite materials, DOI 10.1177/0021998313496592.

[22] Tribological Behavior of Hybrid $\left(\mathrm{LM} 25 \mathrm{Al}+\mathrm{SiC}+\mathrm{TiO}_{2}\right)$ Metal Matrix Composites. G Elagno and BK Raghunath. International conference on Design and Manufacturing 2013. Procedia Engineering 64 (2013) 671680 .

[23] Characteristics of Aluminium and Magnesium Based Nanocomposites Processed Using Hybrid Microwave Sintering. Wong wai Leong Eugene, Manoj Gupta. Journal of Microwave Power and Electromagnetic Energy, 44(1), 2010, pp 14-27. 